\title{
The Healthy -Unhealthy Benefit of Vegetarian Diet and How to Reduce the Unhealthy Benefit?
}

\author{
Rosa Lelyana* \\ Medicine Faculty of Diponegoro University, Indonesia \\ *Corresponding author: Rosa Lelyana, Medicine Faculty of Diponegoro University, Semarang, Indonesia
}

Submission: May 12, 2018; Published: July 06, 2018

\begin{abstract}
Many diseases related to diet habit that we have chosen. If you choose more fatty foods in your daily dietary consumption, the risk of suffering from various diseases will be more often than you will get for suffering if you reduce various fatty foods. Actually we still need to consume fatty foods for our daily needs. The needs of carbohydrates, fats and proteins and the needs of vegetables and fruits still require consideration or calculation that suitable with the needs and daily activities. Lately some people have chosen to switch to a vegetarian diet. Actually, vegetarian diet is a very interesting diet for apart of people in the world but still uncommon habit for apart of people, too. The vegetarian diet is still an awkward thing for some people. This diet is not fully understood by apart of people although this diet is safety if consumers fully understand about the diet. The purpose of this review study is to understand the benefits of a vegetarian diet for our healthy body.
\end{abstract}

Keywords: Vegetarian; Diet; Health; Unhealthy; Benefit

\section{Introduction}

Apart of people love to eat vegetables. The examples of vegetables are carrots, beans, lentils, celery, cabbage, broccoli, mustard greens, red spinach, green spinach and others. But, vegetarian diet is not the same meaning of vegetables diet. Although it can be assume that vegetarian from the word of vegetable, but it can be assume, too that vegetarian from the word of dietarian.

There are many types of vegetarian diet [1] and has been a lot of informations about the vegetarian diet. However, there are people who do not like or do not want to become a person who consume only vegetables. This is maybe due to the lack of convincing information and evidence of research results on the benefits of a vegetarian diet. Therefore, this article will discuss about the benefits of a vegetarian diet and how to reduce the unhealthy benefit.

\section{Methods}

Sytematic review based on several international journal articles selected through keywords that have been published and can be viewed / read online on the internet.

\section{Results and Discussion}

Healthy benefits of vegetarian diet:Actually the health benefits derived from a vegetarian diet depend on the type of vegetarian diet that is chosen for consumption. Different types of vegetarian diets that one chooses will affect the results of the benefits gained.

The general health benefits to be gained from consuming a vegetarian diet are:
1. Reduce consumption of saturated fat, cholesterol and risk of chronic diseases [2]. It is associated with high fiber content due to vegetarian diet so that the possibility of accumulation of body fat will be reduced.

2. Reduce the heart disease and the risk of high blood pressure/hypertension incidence [3-7]. The high consumption of fiber with the content of antioxidants in the body consuming a vegetarian diet than the consumption of saturated fat and cholesterol resulting in fat deposits and cholesterol in the body is reduced so that the proinflamasi response will also be reduced. High consumption of fat and fat accumulation in the body will increase the pro-inflammatory response.

3. Reduce the diseases related to gastrointestinal problem and lung cancer [5] and also the risk of cancer incidence predominantly for colon cancer [3-5]

4. Reduce the risk of diverticular disease $[3,4]$

5. Reduce osteoporosis and rheumatoid arthritis risk incidence $[3,4]$

6. Reduce constipation [5]

7. Lower concentration of uric acid, high sensitivity C-reactive protein(hsCRP) and triacylglycerol $[8,9]$

8. Increase consumption of antioxidants and fiber consumption in the body [2] and increase the level of plasma fasting 
ascorbic acid / higher fasting plasma ascorbic acid concentration $[9,10]$. It also contains many phytochemicals, Mg,vitamin E, folic acid, n-6 PUFA. However low cholesterol, total fat, saturated fatty acids, sodium, Fe2+, zinc, vitamin A, B12, D and n-3PUFA. Low vitamin B12 and n-3PUFA levels are risk factors for noncommunicable disease in vegetarian dietary consumption because it is associated with elevated plasma homocysteine levels, mean platelet volume and platelet aggregability than omnivore diet [10].

9. Vegan food without cooking or called living food (LF) or uncertified vegan food is beneficial for rheumatoid diseases where the inflammatory process is the most important thing in the management of this disease. Consumers of vegetarian diet rich in fiber, lignin and excretion of polyphenols such as enterodiol and enterolactone in their body [11] is food for rheumatoid diseases which is inflammatory process is the most important thing in the management of this disease. Consumers of the vegetarian diet have higher levels of foliate in the body than omnivore but lower vitamin B-12 [12].

10. Consumers of a vegetarian diet have low levels of total cholesterol, LDL-C and hs-CRP / high-sensitivity C-reactive protein than omnivore [13].

11. Similarly, other studies have shown low levels of inflammatory markers, especially lipoprotein associated phospholipase A2 (Lp-PLA2) [14].

\section{Unhealthy benefit of vegetarian diet}

Homocysteine levels are higher in vegetarian diet consumers than omnivore [13]. Other studies suggest that vegetarian diet consumers have high levels of hs-CRP and triacylglycerol [14]. Consumers of vegetarian diets have risk factors for getting the non-communicable diseases [10] such as increased plasma homocysteine levels [10,12-14], mean platelet volume and platelet aggregability $[10,12]$. This is because the vegetarian consumers has low levels of vitamin B12 and n-3 PUFA [10], vitamin B6, valine, isoleucine, leucine, lysine, alanine, arginine but higher levels of glycine [12] so it is necessary to add vitamin B12 to prevention of non-communicable disease [13] and even increased intake of n-3 PUFA [10]. The level of $25(\mathrm{OH}) \mathrm{D}$ is not associated with vegetarian state but there are other factors, which more closely related to vitamin D supplementation, skin pigmentation and degree number of skin pigmentation then intensity of sun exposure affecting s25 $(\mathrm{OH})$ D level than diet / food consumption [15-18].

In a vegetarian diet with low protein intake and low amino acid sulphurwill result in subclinical protein malnutrition. Finally, hyperhomocysteinemia will boost the sensitivity for getting the risk of cardiovascular disease $[19,20]$.

A lower protein intake can be experienced by vegetarian consumers, so stress conditions will also increase the need for protein so that endogenous nitrogen supply will decrease. Then, the body will try to maintain methionine homeostasis so that hyperhomocysteinemia occurs and eventually the risk of cardiovascular disease increases [20]. Thus, homocysteine is an amino acid containing sulphur, and the level of homocystein will increase in case of body stress due to the body's efforts in maintaining methionine homeostasis. Homocysteine is an amino acid formed during demethylationmethionine [21]. The level of homocysteine will increase in individuals with Inflammatory Bowel Disease [22] and vegetarian diet, but more normal homocysteine (tHcy / total homocysteine) total serum levels in a person consuming omnivore $\operatorname{diet}[12,23,24]$.

Consumers of the vegetarian dietare potentially atrisk forvitamin B12 deficiency than the omnivore diet group because the source of vitamin B12 is found in animal products. Hyperhomocysteine due to vitamin B12 deficiency is a major independent biomarker of chronic disease $[24,25]$. The precautionary way to avoid vitamin B12 deficiency is to take supplements containing vitamin B12 regularly [26]. As it is known that the level of foliate plasma and vitamin B12 affect metabolism of homoycsteine where they are cosubstrate and cofactor [27]. So the status of vitamin B should be considered in order not to occur hyperhomocysteine [28].

A study suggests that the mood improvements in the form of reduced stress and anxiety on vegetarian dietary consumption rather than omnivore diet, although the results are inconsistent, may be related to differences in research methodology [29]. There is an inconsistent result about the improvement of mood on the vegetarian diet. This is supported by the results of a study stating that vegetarian dieters have low levels of vitamin B12 [10,30,31] and omega 3 long chain / n-3 PUFA [10] but high folate [31]. Low levels of vitamin B12 (vitamin B12 found in animal protein) and low levels of n-3 PUFA in vegetarian diet are risk factors of noncommunicable disease [10] and major depressive disorder [30]. The nutritional status of a vegetarian diet consumers will affect the neuronal function and synaptic plasticity of brain activity which relevant to the onset and maintenance function of mental disorders $[30,32,33]$. In Western countries also support this study that there is a link between the vegetarian diet and the increased risk of mental disorders, but there is no evidence that the vegetarian diet is the etiology of mental disorders [30].

\section{How to reduce the unhealthy benefit of vegetarian diet?}

The deficiency of protein intake due to diet of vegetarian diet is replaced by using soybean and bean (or plant protein dense product) products [34] and cereals [31]. In addition, it is necessary to take vitamin B12 supplements to avoid vitamin B12 deficiency [31]. Vitamin B12 is found in animal protein like meats or processed meats, although the consumption of meat, especially red meat and processed meats increase the risk of some types of cancer, so need to eliminate such foods. Actually a vegetarian diet is a strategy to reduce the risk of cancer [35] and effectively prevent metabolic syndrome than conventional therapy [36].

N-3 fatty acid deficiency is improved by eating fish such as tuna, mackerel, sardines, salmon and herring because these fish contain high levels of long chain omega-3s $[37,38]$. Omega 3 content in fish depends on the food consumed fish [39]. In addition to fish, low level of omega 3 is also found in cows but also depends on the food 
consumed food consumed cows [40].Vegetarian diet also consume drink coffee less than non vegetarian diet consumers [41,42]. Actually coffee has benefit as antioxidant [43], may boost immune system [44] and reduce body weight [45,46]. Many results study has proved the benefit of coffee consumption in Figure 1.

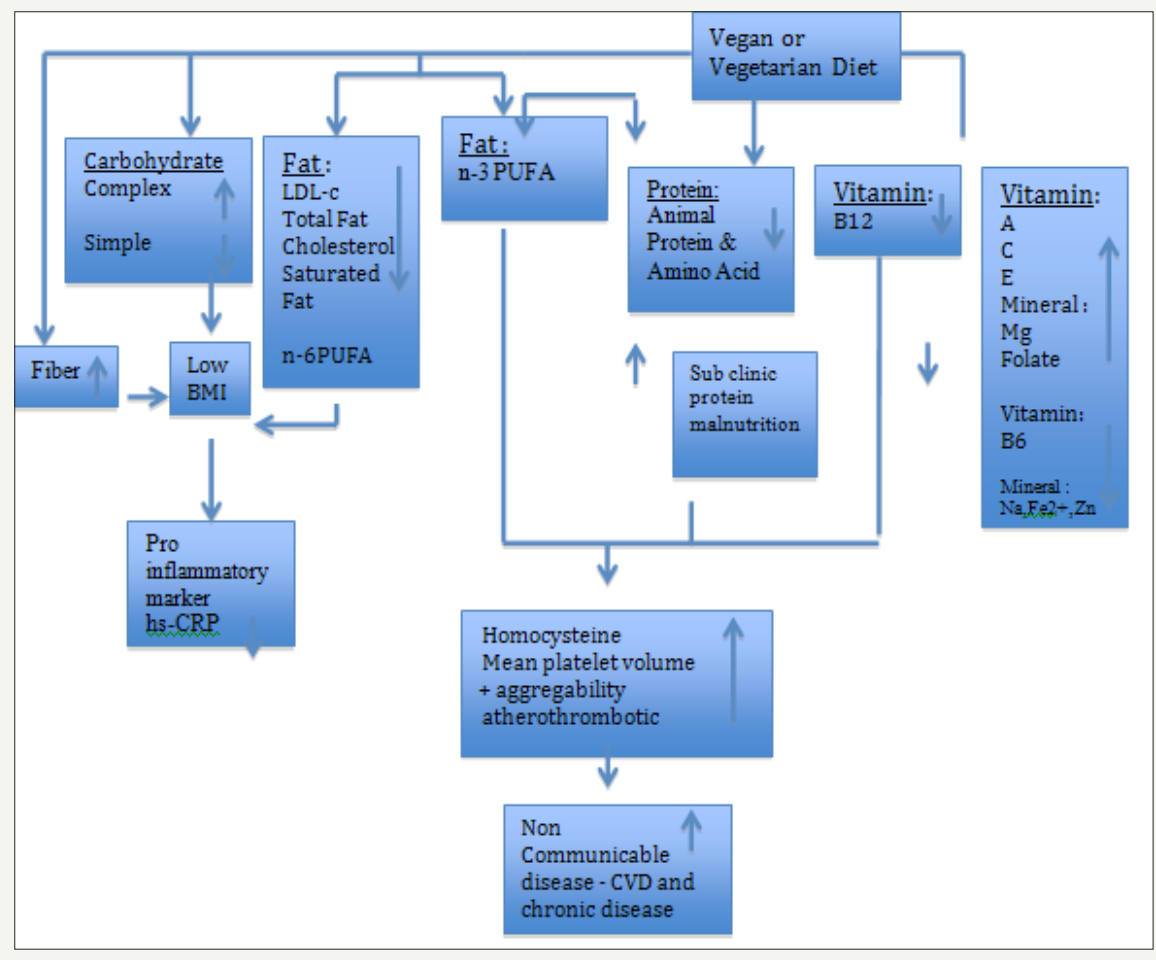

Figure 1. Healthy and Unhealthy Benefit of Vegetarian Diet (Rosa Lelyana modification's, 2018).

\section{Conclusion}

Many healthy benefits of vegetarian diets, but we have to give B12 supplementation for disease prevention of non communicable disease with vegetarian diet.

\section{References}

1. Pawlak R (2017) Vegetarian diets in the prevention and management of diabetes and its complications. Diabetes Spectr 30(2): 82-88.

2. Bredbenner CB, Beshgetoor D, Moe G, Berning JV (2007) Diet. In: Wardlaw's Perpectives in Nutrition Text Book. $\left(8^{\text {th }} e d n\right)$, McGraw Hill Companies, Inc. New York, USA, p.250.

3. Sizer FS, Whitney EV (2008) Meat Containing Diets: What Are the benefits and pitfalls? In Nutrition: Concepts and controversies text book. International Student Edition, $\left(11^{\text {th }}\right.$ edn), Thomson Wadsworth, USA, p. 216.

4. Leitzmann CV (2005) Diet: What are the advantages? Forum of Nutrition 5: $147-156$

5. Sabate J (2003) The contribution of vegetarian diets to health and disease: a paradigm shift? Am J Clin Nutr 78(suppl): 502S

6. Leitzmann C (2014) Vegetarian nutrition, past, present and future. Am J Clin Nutr 100(suppl I): 496S-502S.

7. American Dietetic Association Dietitians of Canada (2003) Position of the American Dietetic Association and Dietitian of Canada: Vegetarian Diets. J Am Diet Assoc 103(6): 748-765.

8. Alpers DH, Taylor BE, Bier DM, Klein S (2015) Use of Diets and Dietary
Components in Clinical Practice In: Manual of Nutritional Therapeutics Text Book. ( $6^{\text {th }}$ edn), Wolters Kluwer, Philadelphia, USA, pp. 488-490.

9. Szeto YT, Kwok TC, Benzie IF (2004) Effects of long term vegetarian diet on biomarkers of antioxidant status and cardiovascular disease risk. Nutrition 20(10): 863-866.

10. Li D (2014) Effect of the vegetarian diet on non communicable diseases. J Sci Food Agric 94(2): 169-173.

11. Hanninen, Kaartinen K, Rauma AL, Nenonen M, Torronen R, et al. (2000) Antioxidants In vegan diet And rheumatic disorders. Toxicology 155(13): $45-53$

12. Hung CJ, Huang PC, Lu SC, Li YH, Huang HB, et al. (2002) Plasma homocysteine levels in Taiwanese vegetarians are higher than those of omnivores. J Nutr 132(2): 152-158.

13. Chen CW, Lin YL, Lin TK, Lin CT, Chen BC, et al. (2008) Total cardiovascular risk profile of Taiwanese vegetarians. Eur J Clin Nutr 62(1): 138-144.

14. Chen CW, Lin CT, Lin YL, Lin TK, Lin CL (2011) Taiwanese female vegetarians have lower lipoprotein-associated phospholipase A2 compared with omnivores.Yonsei Med J 52(1): 13-19.

15. Turner McGrievy G, Mandes T, Crimarco A (2017) A Plant-based diet for overweight and obesity prevention and treatment. J Geriatr Cardiol 14(5): 369-374

16. Sabate J, Wien M (2010) Vegetarian diets and childhood obesity prevention. Am J Clin Nutr 91(5): 1525S-1529S.

17. Carneiro ACLL, Resende AS, Santos EA, Silva GMO, Maciel PF (2014) The impact of vegetarian diet in the prevention of type 2 Diabetes Mellitus. Demetra: Food, Nutrition \& Health 9(3): 681-706. 
18. Chan J, Jaceldo Siegl K, Fraser GE (2009) Serum 25-hydroxyvitamin D status of vegetarians, partial vegetarians, and nonvegetarians: the Adventist Health Study-2. Am J Clin Nutr 89(5): 1686S-1692S.

19. Ingenbleek Y, McCully KS (2012) Vegetarianism produces subclinical malnutrition, hyperhomocysteinemia and atherogenesis. Nutrition 28(2): 148-153.

20. Ingenbleek Y, Hardillier E, Jung L (2002) Subclinical protein malnutrition is a determinant of hyperhomocysteinem. Nutrition 18(1): 40-46.

21. Erzin Y, Uzun H, Celik AF, Aydin S, Dirican A (2008) Hyperhomocysteinemia in inflammatory bowel disease patients without past intestinal resections: correlations with cobalamin, pyridoxine, folate concentrations, acute phase reactants, disease activity, and prior thromboembolic complications. J Clin Gastroenterol 42(5): 481-486.

22. Oussalah A, Guéant JL, Peyrin Biroulet L (2011) Meta-analysis hyperhomocysteinaemia in inflammatory bowel diseases. Aliment Pharmacol Ther 34(10): 1173-1184.

23. Karabudak E, Kiziltan G, Cigerim NA (2008) Comparison of some of the cardiovascular risk factors in vegetarian and omnivorous Turkish females. J Hum Nutr Diet 21(1): 13-22.

24. Obersby D, Chappell DC, Dunnett A, Tsiami AA (2013) Plasma total homocysteine status of vegetarians compared with omnivores:a systematic review and meta-analysis. Br J Nutr 109(5): 785-794.

25. Herrmann W, Schorr H, Obeid R, Geisel J (2003) Vitamin B-12 status, particularly holotranscobalamin II and methylmalonic acid concentrations, and hyperhomocysteinemia in vegetarians. Am J Cli Nutr 78(1): 131-136

26. Pawlak R, Parrott SJ, Raj S, Cullum Dugan D, Lucus D (2013) How prevalent is vitamin $\mathrm{B}(12)$ deficiency among vegetarians? Nutr Rev 71(2): 110-117.

27. Lim HS, Heo YR (2002) Plasma total homocysteine, folate and vitamin B12 status in Korean adults. J Nutr Sci Vitaminol (Tokyo) 48(4): 290297.

28. Chen KJ, Pan WH, Yang FL, Wei IL, Shaw NS, et al. (2005) Association of B vitamins status and homocysteine levels in elderly Taiwanese. Asia Pac Clin Nutr 14(3): 250-255.

29. Beezhold B, Radnitz C, Rinne A, DiMatteo J (2015) Vegans report less stress and anxiety than omnivores. Journal Nutritional Neuroscience An International Journal on Nutrition, Diet and Nervous System. Nutr Neurosci 18(7): 289-296

30. Michalak J, Zhang XC, Jacobi F (2012) Vegetarian diet and mental disorders: results from a representative community survey. Int J Behav Nut Phys Act 9: 67.

31. Gilsing AMJ, Crowe FL, Wright ZL, Sanders TAB, Appleby PN, et al (2010) Serum concentrations of vitamin B12 and folate in British male omnivores, vegetarians, and vegans: results from a cross-sectional analysis of the EPIC-Oxford cohort study. Eur J Clin Nutr 64(9): 933-939.
32. Young G, Conquer J (2005) Omega-3 fatty acids and neuropsychiatric disorders. Reprod Nutr Dev 45(1): 1-28.

33. Perica MM, Delas I (2011) Essential fatty acids and psychiatric disorders. Nutr Clin Pract 26(4): 409-425.

34. Allès B, Baudry J, Méjean C, Touvier M, Péneau S, etal. (2017) Comparison of sociodemographic and nutritional characteristics between selfreported vegetarians, vegans, and meat-eaters from the nutri net-sante study. Nutrients 9(9).

35. Lanou AJ, Svenson B (2010) Reduced cancer risk in vegetarians: an analysis of recent reports. Cancer Manag Res 3: 1-8.

36. Turner McGrievy G, Harris M (2014) Key elements of plant-based diets associated with reduced risk of metabolic syndrome. Curr Diab Rep 14(9): 524.

37. Harris WS (2010) Omega-3 fatty acids. In: Coates PM, Betz JM, Blackman MR (Eds.), Encyclopedia of Dietary Supplements. $\left(2^{\text {nd }} e d n\right)$, Informa Healthcare, New York, USA, pp. 577-586.

38. U.S Department of Health and Human Services (2018) NIH National Institute of Healths. Office of Dietary Supplements. Omega-3 Fatty acids.

39. Miller MR, Nichols PD, Carter CG (2008) n-3 Oil sources for use in aquaculture-alternatives to the unsustainable harvest of wild fish. Nutr Res Rev 21(2): 85-96.

40. Van Elswyk ME, McNeill SH (2014) Impact of grass/forage feeding versus grain finishing on beef nutrients and sensory quality: The U.S. experience. Meat Sci 96(1): 535-540.

41. Elorinne AL, Alfthan G, Iris Erlund I, Kivimäki H, Paju A, et al. (2016) Food and nutrient intake and nutritional status of finnish vegans and non-vegetarians. PLoS One 11(2): e0148235.

42. Burkholder N, Siapco G, Haddad Tabrizi S, Sabate J (2014) Nutrition Comparison of food intake of vegetarian and non-vegetarian adolescents. The Faseb Journal 28(1).

43. Lelyana R (2015) Total phenolic acid contents in some commercial brands of coffee from Indonesia. Journal of Medicinal Plant and Herbal Therapy Research 3(2): 27-29.

44. Lelyana R (2017) Drinking coffee for life style and maintenance immune system. Nanomed Nanotechnol 8: e146.

45. Lelyana R (2017) Underlying mechanism of coffee as inhibitor adipogenesis for complementary medicine use in obesity. J Nanomed Nanotechnol 8: 425

46. Lelyana R (2016) Effect of coffee daily consumption on uric acid level and body weight to prevent metabolic syndrome. Nanomed Nanotechnol 7(5): 400
Creative Commons Attribution 4.0 International License

For possible submissions Click Here

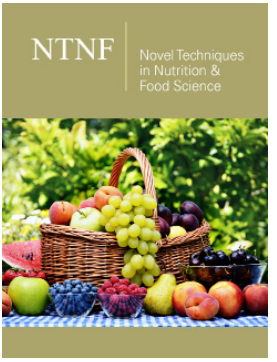

Novel Techniques in Nutrition and Food Science

\section{Benefits of Publishing with us}

- High-level peer review and editorial services

- Freely accessible online immediately upon publication

- Authors retain the copyright to their work

- Licensing it under a Creative Commons license

- Visibility through different online platforms 